Addendum

\title{
Editorial Expression of Concern: DNA-guided genome editing using the Natronobacterium gregoryi Argonaute
}

Feng Gao, Xiao Z Shen, Feng Jiang, Yongqiang Wu \& Chunyu Han

Nat. Biotechnol. 34, 768-773 (2016); published online 2 May 2016; addendum published after print 28 November 2016

The editors of Nature Biotechnology are issuing an editorial expression of concern regarding this article to alert our readers to concerns regarding the reproducibility of the original results. At this time, we are publishing the results of three groups (http://dx.doi.org/10.1038/nbt.3753) that have tried to reproduce the results in the critical Figure 4 in the original paper by Han and colleagues, which demonstrates editing of endogenous genomic loci in mammalian cells. None of the groups observed any induction of mutations by NgAgo at any of the loci or under any of the conditions tested above the sensitivity of the assays used. Similar results have been recently reported by a different group of authors in Protein \& Cell (doi:10.1007/s13238-016-0343-9).

We are in contact with the authors, who are investigating potential causes for the lack of reproducibility. The authors have been informed of this statement. While the investigations are ongoing, Chunyu Han and Xiao Z. Shen agree with this editorial expression of concern. Feng Gao, Feng Jiang and Yongqiang Wu do not feel that it is appropriate at this time.

We will update our readers once these investigations are complete.

\section{Erratum: Drugging the gut microbiome}

\section{Ken Garber \\ Nat. Biotechnol. 33, 228-231 (2015); published online 6 March 2015; corrected after print 12 October 2016}

In the version of this article initially published, on p.231, left-hand column, the maker of linaclotide was said to be Redwood rather than Ironwood Pharmaceuticals. In addition, linaclotide is no longer referred to as a "homolog of the enterotoxin peptides," but as "similar to the enterotoxin peptides," and it has been clarified to be "rationally designed." The errors have been corrected in the HTML and PDF versions of the article.

\section{Erratum: An optical probe of synaptic plasticity}

Tal Laviv \& Ryohei Yasuda

Nat. Biotechnol. 35, 26-27 (2017); published online 10 January 2017; corrected after print 30 March 2017

In the version of this article initially published, reference 1 was missing the author's first initial. The error has been corrected in the HTML and PDF versions of the article.

\section{Corrigendum: Response to "Railroading at the FDA"}

Francesco Muntoni, Sue Fletcher \& Steve Wilton

Nat. Biotechnol. 35, 207-209 (2017); published online 7 March 2017; corrected after print 30 March 2017

In the version of this article initially published, F.M. was credited for giving input on study design and data analysis, which he did not. The error has been corrected in the HTML and PDF versions of the article.

\section{Corrigendum: A FRET sensor enables quantitative measurements of membrane charges in live cells}

Yuanqing Ma, Yui Yamamoto, Philip R Nicovich, Jesse Goyette, Jérémie Rossy, J Justin Gooding \& Katharina Gaus Nat. Biotechnol. doi:10.1038/nbt.3828; published online 13 March 2017; corrected after print 31 March 2017

In the version of this article initially published, in the Figure 1 legend, the following text was inserted: "(d), and the average FRET efficiencies in transfected COS-7 cells (e)"; in Figure 2d, the right-hand $y$ axis was given as "PS fusion," rather than "DOTAP fusion"; in text beneath Figure 2, figure callouts were corrected and additional text added as follows: "275 mM (Fig.1d,e)" should read "275 mM (Fig. 1d)", "9 mM (Fig. 1e)" should read "9 mM (Fig. 1f)", "FI exhibited no" should be "FI exhibited different FRET efficiencies in intact cells (Fig. 1e) and no," "strength (Fig. 1c-f)" should be "strength (Fig. 1c,d,f)," "reach 50\% in" should be "reach 50\% change in"; in text beneath Figure 3, "MCS ${ }^{+}($Fig. 2 e-g)" should be "MCS (Fig. 2e,f)"; in Figure 3 legend, "s.e." should read "s.e.m." The errors have been corrected in the HTML and PDF versions of the article. 